\title{
REVIEWS
}

\section{Symptomatic and Palliative Care for Stroke Survivors}

\author{
Claire J. Creutzfeldt, $M D^{7}$, Robert G. Holloway, $M D, M P H^{2,3}$, and Melanie Walker, $M D^{7}$
}

'Department of Neurology, University of Washington Harborview Medical Center, Seattle, WA, USA; ${ }^{2}$ Department of Neurology, University of Rochester Medical Center, Rochester, NY, USA; ${ }^{3}$ Department of Medicine, Division of Palliative Care, University of Rochester Medical Center, Rochester, NY, USA.

Stroke is the leading cause of disability and one of the most common causes of death worldwide. Outside the setting of acute management, secondary prevention and stroke rehabilitation, little has been written to address the ongoing symptomatic and palliative needs of these patients and their families. In this literature review, we look beyond secondary prevention with the aim of providing evidence-informed management guidelines for the myriad and often under-recognized symptomatic and palliative care needs of stroke survivors. Some of the most common and disabling post-stroke symptoms that are reviewed here include central poststroke pain, hemiplegic shoulder pain, painful spasticity, fatigue, incontinence, post-stroke seizures, sexual dysfunction, sleep-disordered breathing, depression and emotionalism. We review the role of caregivers and explore ways to support them and, lastly, remind the reader to be perceptive to the patient's spiritual needs. The literature is most robust, including controlled trials, for central post-stroke pain and depression. Synthesis and discussion outside these areas are frequently limited to smaller studies, case reports and expert opinion. While some data exists to guide informed decision-making, there is an urgent need to document best practice and identify appropriate clinical standards for the full spectrum of symptoms experienced by stroke survivors. We present the current and established data to aid health care providers in symptomatic and palliative management of stroke survivors.

KEY WORDS: stroke; palliative care; symptom management.

$\mathrm{J}$ Gen Intern Med 27(7):853-60

DOI: $10.1007 / \mathrm{s} 11606-011-1966-4$

(c) Society of General Internal Medicine 2012

\section{INTRODUCTION}

Stroke is the leading cause of disability in the US. Of the more than 4,500,000 stroke survivors alive in the United States today, $15 \%$ to $30 \%$ are permanently disabled and $20 \%$ require institutional care at 3 months after stroke onset. ${ }^{1}$ Clinical practice guidelines for stroke survivors are

Received July 11, 2011

Revised October 13, 2011

Accepted November 30, 2011

Published online January 19, 2012 focused almost entirely on secondary stroke prevention or management of devastating injury ${ }^{2,3}$ and stroke rehabilitation, ${ }^{4-6}$ with little focus on palliative and supportive symptom management.

The role of palliative care, while well established for oncologic and chronic progressive neuromuscular diseases, is less clear for patients with stroke. The tendency among practitioners is to recommend palliative management only in the final stages of life, rather than to explore quality-oflife issues throughout the course of a disease. The clinical trajectory of stroke is quite different from many other disorders, such as ALS, lung cancer or chronic heart failure, where progressive disability ultimately leads to an untimely death. A stroke transitions an individual acutely into a new functional status with likely dependencies, and transitions their loved ones into a situation that requires an entirely new degree of adaptation, vigilance and compromise. Post-stroke symptoms encompass body and mind, and literature is scarce on the detection and management of palliative needs specific to survivors, as well as the role of specialists in palliative care for this group. ${ }^{7}$

This review is aimed at primary care, neurology, palliative care providers and stroke specialists alike, who in addition to reducing mortality and improving functional outcome aim to improve the quality of life of stroke survivors by recognizing and treating the troubling symptoms that occur after ischemic stroke or intraparenchymal hemorrhage.

\section{LITERATURE SEARCH}

References for this review were identified through PubMed searches of English, Spanish and German languages with the search term stroke combined with the respective terms central pain, hemiplegic shoulder pain, spasticity, fatigue, incontinence, post-stroke seizures, sexual dysfunction, sleep-disordered breathing, depression, anxiety and emotionalism. While we limited our search to review articles, clinical practice guidelines and randomized controlled trials as well as those published after 1995, we also identified articles through searches of our own files. In addition, we reviewed the references of these articles to identify any other important studies, including those with publication 
dates prior to 1995 (see Fig. 1). Each of the authors performed data extraction, assessed data quality and screened the relevant abstracts and articles based on their expertise and language skills. Disagreements were resolved by consensus. For each symptom, we identified available treatments and graded the level of evidence based on published criteria. ${ }^{8}$ We organized the symptoms according to the WHO definition of palliative care (see below) into pain, physical, psychological, social and spiritual categories.

\section{SYMPTOM DETECTION AND MANAGEMENT}

Palliative care seeks to prevent and relieve suffering "by means of early identification and impeccable assessment and treatment of pain and other problems, physical, psychosocial, and spiritual." 9

Detecting and managing symptoms in patients with stroke should be a central goal of all health care practitioners caring for stroke survivors. While many of these symptoms occur in the general population, stroke patients are frequently less able to offer details or describe their concerns. The clinician should be aware of the prevalence of these symptoms and attentive to their presence. Approaches to some of the more common symptoms observed post-stroke are outlined below. The table provides a list of symptoms with specific treatment recommendations and a summary of evidence. The review highlights several observations. First, symptoms can be extremely troubling to previously healthy patients and occur in all stages of stroke. Findings may present at any time post-stroke, even chronically, and may be unmasked or exacerbated in those who are actively dying. Second, stroke symptoms can adversely impact recovery, quality of life and mortality. Third, particular attention is needed for patients with impaired communication since they are frequently unable to articulate their complaints. ${ }^{10}$

\section{PAIN}

Chronic pain after stroke occurs in about a quarter of stroke survivors, it interferes with rehabilitation and is associated with a reduced quality of life. ${ }^{11}$ Predictors of pain are younger age, female gender, higher NIHSS and higher HbA1c. ${ }^{11}$ Most common types of pain are central poststroke pain (CPSP) and hemiplegic shoulder pain (HSP), painful spasticity and tension-type headache. ${ }^{12}$
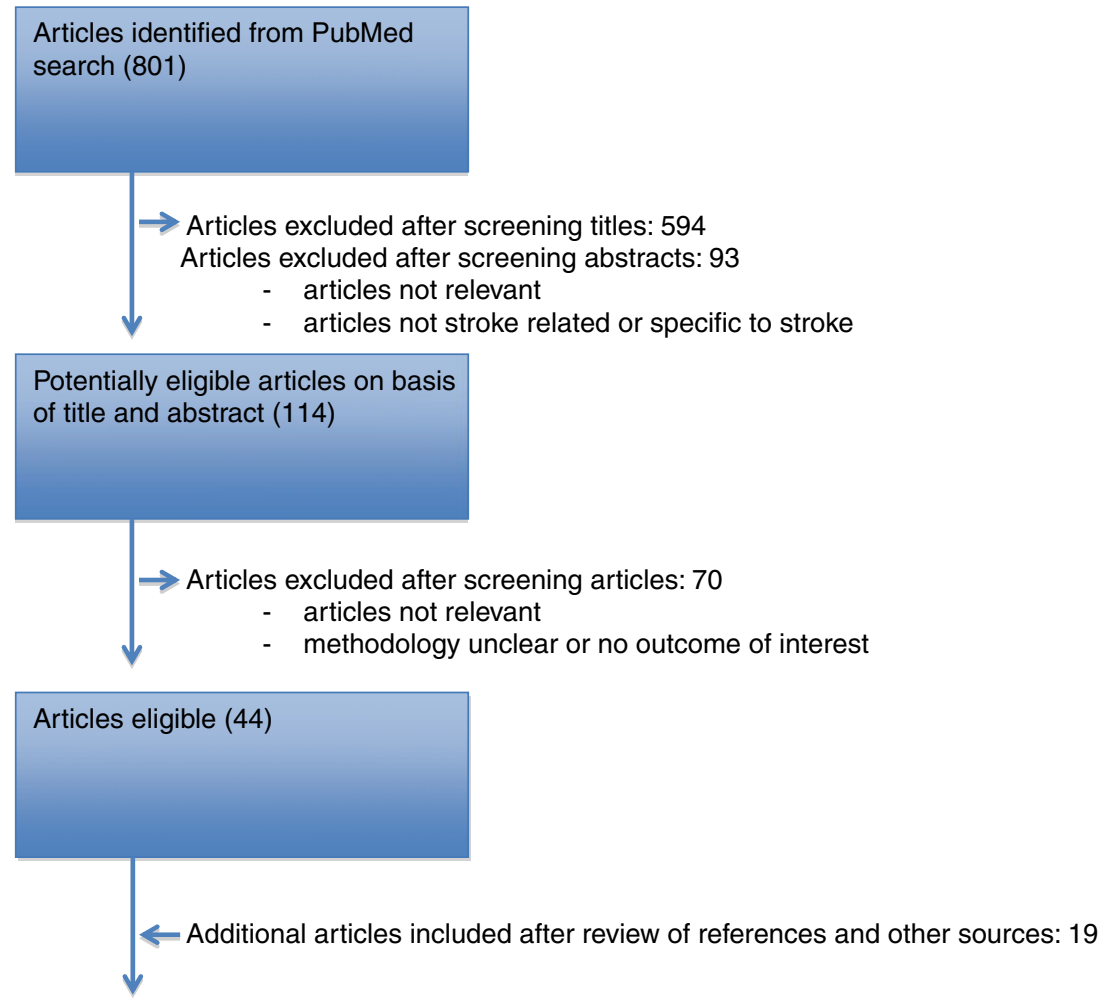

Articles included (63)

Figure 1. Literature Search. 
CPSP. CPSP is a neuropathic pain syndrome that arises within weeks to months after the stroke as a direct consequence of the lesion, affecting the corresponding body part. Prevalence is between 1 and 12\%, and is highest after infarction in areas responsible for pain perception and processing (lateral medullary plate, ventroposterior part of the thalamus, sensory cortex ${ }^{12}$ ). Pain can be spontaneous or evoked, and spontaneous pain can be continuous or intermittent. Sensory abnormalities such as dysesthesias (unpleasant or painful), allodynia (non-painful stimulus such as touch or brush felt as pain) and hyperalgesia (painful stimulus is even more painful) are common. Treatment of CPSP is challenging, and large controlled trials are lacking. At present, the tricyclic antidepressant (TCA) amitriptyline is the drug of choice, but this recommendation is based on a single study of 15 patients aged $<75$ years. ${ }^{13}$ The rationale for using other antidepressants stems from the robust evidence for treatment of neuropathic pain, with TCAs and some SNRIs (selective noradrenergic receptor inhibitors) showing effectiveness but not SSRIs (selective serotonergic receptor inhibitors). ${ }^{14}$ Among anticonvulsant agents, lamotrigine was moderately effective in 30 patients with CPSP, ${ }^{15}$ while neither pregabalin ( ${ }^{16} ; 219$ patients) nor carbamazepine (13; 14 patients) had meaningful pain relief. The recommendations for gabapentin are based on its effectiveness in the treatment of a range of neuropathic pain syndromes not specific to CPSP. ${ }^{17}$ Opioids are not effective for CPSP. ${ }^{18}$

$\boldsymbol{H S P}$. HSP usually develops within weeks to months after the stroke, and its prevalence rises with the degree of motor impairment $(83 \%$ among patients with zero arm motor function $^{19}$ ). Post-stroke shoulder pain is thought to result from sensory and motor deficits, subluxation and limited passive range of movement. Spastic shoulder pain may be part of the picture, and shows a pattern of adduction and internal rotation of the shoulder. Physical therapy with a passive (lateral) range of motion (ROM) and shoulder girdle strengthening is recommended based on the proposed etiology, but there is no available evidence that either intervention reduces pain or improves ROM in the hemiplegic shoulder. ${ }^{20} \mathrm{~A}$ shoulder sling during ambulation may support the arm to reduce pain and prevent upper extremity trauma. Any overhead movement should be avoided as it may worsen pain and subluxation. Ice, heat and soft tissue massage as well as oral analgesics (e.g., nonsteroidal anti-inflammatory agents) all have temporizing pain relief. Promising interventions that require further study include intramuscular injection of Botox $\mathrm{A}$, intra-articular steroid injections and neuromuscular electric stimulation. ${ }^{21,22}$ In contrast to CPSP, good recovery is likely, with the majority of patients improved or pain free at 6 months. ${ }^{23}$

(Painful) Spasticity. Prevention and palliation of spasticity are best done with physical therapy, antispastic positioning and range of motion exercises. Baclofen, tizanidine and dantrolene are recommended for the treatment of post-stroke spasticity based on single, small studies. ${ }^{6}$ However, side effects are common and mainly include sedation or somnolence (baclofen and tizanidine, to a lesser extent dantrolene), confusion and weakness (baclofen) and dizziness (tizanidine); patients taking dantrolene require periodical monitoring of liver function tests given the potential for hepatotoxicity. ${ }^{24}$ The use of local injections of botulinum toxin may be recommended in selected patients, in particular with upper extremity (wrist and finger) spasticity where reducing tone may improve function. ${ }^{6,25}$

\section{PHYSICAL}

Fatigue. Like most other chronically ill populations, stroke survivors commonly suffer from fatigue with a prevalence of over $50 \%$. It is correlated with both depression and disability, but is also common in stroke survivors with neither. ${ }^{26}$ Other contributing factors may be older age, female sex and mental health; fatigue is associated with reduced long-term survival. ${ }^{27}$ Fatigue is significantly more common in patients after minor strokes than in patients after TIA, suggesting that it may be a direct consequence of the brain injury. ${ }^{28}$ Stroke survivors and their caregivers commonly feel unprepared for significant fatigue and struggle to adapt, with fatigue having a debilitating influence upon daily occupational performance and roles, including social participation, return to work, driving, reading and sleeping. ${ }^{29}$

A comprehensive assessment is key and includes screening questions for depression, obstructive sleep apnea and laboratory workup for hematologic, metabolic and endocrine disorders. Except for cause-specific treatment in cases such as hypothyroidism, anemia, malnutrition, depression, dehydration, infection or sleep apnea, no treatment has yet been shown to provide benefit. ${ }^{30}$ Non-pharmacological treatment should be recommended, such as diet, exercise and assistive technologies, since deconditioning may also contribute to overall fatigue. The use of brain-stimulating drugs may sound enticing, but these agents should be used cautiously because of their known association with vascular events. Modafinil was studied in 23 young patients with mild strokes and was effective in those with brainstem strokes, but not in those with cortical strokes. A $25 \%$ dropout rate was due to adverse effects, most commonly headache and irritability. ${ }^{31}$ Methylphenidate is used as a palliative treatment in other advanced diseases, such as HIV or cancer, ${ }^{32}$ but its response is anecdotal in patients with post-stroke fatigue.

Incontinence. Both urinary and fecal incontinence are underestimated after stroke and associated with increased 
mortality, disability and discharge to institutionalized care. Incontinence can be embarrassing to patients and a major burden on their caregivers once they are discharged home. About $50 \%$ of stroke patients experience incontinence at admission, but this number is reduced to $20 \%$ (urinary) and $10 \%$ (fecal incontinence) by 6 months post-event. Increased age, increased stroke severity, diabetes and other disabling comorbidities increase the risk of urinary incontinence in stroke patients. ${ }^{33}$ Incontinence after stroke is not always central in origin, but may be the result of immobility and impaired ability to communicate. Although there is insufficient evidence regarding the treatment of incontinence after stroke, ${ }^{34}$ general continence care includes early removal of Foley catheters to avoid urinary tract infection, bladder training programs, and prompted voiding and bowel programs. ${ }^{6}$ Constipation is also common following stroke, particularly when mobility is reduced, and requires regular monitoring, bowel programs and appropriate medical treatment. Despite its frequency, little evidence exists for the approach to constipation. A useful bowel regimen in bedridden patients includes a stimulant laxative such as bisacodyl or senna along with an osmolar agent such as milk of magnesia or polyethylene glycol. Stool softeners such as docusate have limited clinical efficacy. ${ }^{35}$

Post-Stroke Seizures and Epilepsy. Stroke is the most common cause of seizures in the elderly. Between 5 and $12 \%$ of patients will suffer one or more epileptic seizures after an ischemic stroke, ${ }^{36,37}$ and the incidence increases with cortical location and clinical severity. ${ }^{36}$ The risk of developing epilepsy (i.e., 2 or more unprovoked seizures) is higher in patients whose first seizure occurred $>2$ weeks after the stroke ("late" post-stroke seizures). Post-stroke seizures have a devastating effect on morale and may further impair already compromised quality of life. The caregiver's initial thought is frequently that their loved one is having another stroke. Informing patients of their heightened risk for post-stroke seizures should be considered, realizing that it may cause increased anxiety. Studies evaluating the effectiveness of anticonvulsant medications for primary prevention of seizure in stroke survivors have not shown convincing benefit. ${ }^{38}$ The American Heart Association (AHA)'s current guidelines do not recommend using preventive anticonvulsants for patients with stroke (who have not had a seizure). ${ }^{2}$ A careful history, examination and review of investigations are important to rule out any reversible causes, such as metabolic disturbances, a new stroke or medications that lower seizure threshold. Once patients develop post-stroke epilepsy, anticonvulsants should be started; the choice of the specific anti-epileptic medication needs to take into consideration comorbidities, medications, preferences and cost. Good evidence exists for lamotrigine (especially in the elderly, also a mood stabilizer, but slow titration is necessary), carbamazepine (long experience, low cost, but an enzyme inducer, and hyponatremia is common in the elderly), levetiracetam (rapid titration, not an enzyme inducer, but has psychiatric adverse effects) and gabapentin (not an enzyme inducer, effective in neuropathic pain, but evidence of efficacy only in the elderly). ${ }^{39,40}$

Sexual Dysfunction. A noticeable decline in sexuality happens after strokes, even in patients with mild or no residual deficit. ${ }^{41}$ Sexual disorders are rarely a consequence of the stroke alone, but rather associated with a variety of psychosocial factors and medical comorbidities. Decreased libido is a common side effect of antihypertensives (beta-blockers) and antidepressant medications, but depression itself also dampens libido. Other important factors are the inability to discuss sexuality and the fear that sexual activity would have adverse medical effects. Loss of desire and the feeling of being less attractive are all understandable in the face of facial drooping, dysphasia, hemiparesis and incontinence. Practical advice to patients and their partners includes spending time together doing activities both enjoy, or just sitting quietly holdings hands or embracing each other and, in the dysphasic patient, early goals of speech-retraining may be to establish a method of saying "I love you." 42 Health providers need to acknowledge the effect of stroke on intimacy and sexuality, and should provide the necessary resources, such as can be found at www.stroke. org ("Hope: The Stroke Recovery Guide") or www. sexualhealth.com (under "Disability \& Chronic Conditions"). ${ }^{42}$ Patients with erectile dysfunction may benefit from Sildenafil (Viagra), which in a low dose $(25 \mathrm{mg})$ was suggested to be safe in a small trial of 12 patients with mild to moderate stroke $^{43}$; sildenafil is a vasoactive drug and should, thus, be used cautiously in patients with vascular disease.

Sleep-Disordered Breathing. More than half of stroke patients suffer from sleep-disordered breathing (SDB), defined as ten or more breathing pauses (apneas) lasting more than $10 \mathrm{~s}$ per hour (a so-called apnea-hypopnea index of $\geq 10 / \mathrm{h}$ ). The frequency is similar in patients with TIA, suggesting a pre-existing or even causal condition. The most common form of SDB is obstructive sleep apnea (OSA), which is caused by collapse of the upper airway. SDB contributes to cardiovascular morbidity and is an important modifiable risk factor. ${ }^{44}$ Even though the association between stroke and SDB is convincing, research is still needed to determine whether the treatment of SDB will prevent recurrent stroke or other vascular events. ${ }^{45}$ A referral to an accredited sleep center should be considered for all stroke patients who may accept CPAP treatment. ${ }^{44}$ 


\section{PSYCHOLOGICAL}

Depression. Post-stroke depression (PSD) affects up to one third of stroke survivors ${ }^{45}$ and should be recognized early, because it impedes rehabilitation, reduces quality of life and increases mortality after stroke. ${ }^{46}$ Whether the use of antidepressant medications can prevent PSD is unclear. ${ }^{47}$ One recent study in non-depressed stroke survivors suggested a benefit of antidepressant medication with regard to motor recovery and also some mood improvement. ${ }^{48}$ Pharmacologic treatment of PSD leads to a reduction in various measures of depression, but the effect on cognitive function or functional outcome is unclear, and adverse events are common, including central nervous system events (confusion, sedation, tremor) and gastrointestinal effects (constipation, diarrhea). ${ }^{46}$ Controlled trials on PSD are essentially limited to TCAs and SSRIs. Although the former are effective in reducing depression, their cholinergic side effects limit their clinical usefulness, especially in older, frail patients with vascular disease. The data on SSRIs for treating PSD are mixed (see Table 1), but their safety profile is more favorable, making them the agents of choice. One study suggested that the SSRI citalopram may be more effective in "anxious depressed" (agitated, irritable) patients, whereas the noradrenergic drug reboxetine may be more effective in "retarded depressed" (mentally and physically slowed down) patients. ${ }^{49}$ While psychological, "talking" interventions (mostly behavioral interventions: identifying symptoms and causes of depression, and identifying and planning pleasant activities) seem promising, their benefit is not yet convincing, ${ }^{46,47,50}$ and their use should be tailored individually.

Anxiety. Anxiety after stroke is common and distressing. It can occur in the acute and non-acute stages of stroke and may be compounded by a fear of stroke recurrence. A generalized anxiety pattern may be seen in up to a third of patients. ${ }^{51}$ The frequency of panic attacks is unknown. Anxiety may accompany depression or delirium, or may result from other distressing physical symptoms. Thus, antidepressant medications (e.g., citalopram ${ }^{52}$ ) may be effective for generalized anxiety or panic pattern symptoms in this setting. If anxiety is severe and if the lifespan is limited, however, benzodiazepines are the drugs of choice. Short-term antipsychotic agents such as haloperidol may also be useful if anxiety is coupled with delirium, but studies specific to stroke are lacking. ${ }^{53}$

Emotionalism. Pathological crying or laughing, or the pseudobulbar affect, can be distressing to both the patient and their families, and occurs in over a tenth of stroke survivors. As with many other symptoms, acknowledgement and education about emotional lability can diffuse potentially uncomfortable situations. While antidepressant medication may reduce the frequency of crying or laughing episodes, ${ }^{54}$ it is difficult to recommend use on these grounds alone. Recently, the FDA approved Nuedexta, a fixed-dose combination of the cough-suppressant dextromethorphan hydrobromide and the antiarrhythmic quinidine sulfate, for treatment of the pseudobulbar affect in patients with amyotrophic lateral sclerosis or multiple sclerosis. ${ }^{55}$ While it has not been studied in this population, Nuedexta may become relevant for stroke patients in the future.

\section{SOCIAL}

Care Giving and Receiving. While coping with ongoing uncertainty and disability, stroke survivors are forced to adapt to a new and often unfamiliar role in their social environment - that of the dependent. While an initial comprehensive social assessment of the patient's family structure, social and cultural networks, lines of communication and medical decision-making is frequently done in the acute setting to guide immediate care, these issues should be readdressed frequently. Women, younger caregivers, those with poor physical health and those caring for patients with severe cognitive, behavioral and emotional changes are at highest risk of caregiver burn-out. ${ }^{56}$ Support programs should focus on increasing self-efficacy, active coping strategies and social support. ${ }^{56}$ If necessary, referrals should be made to appropriate services that meet identified social needs and promote access to care, transportation, rehabilitation, medications, counseling, community resources and equipment.

Caregivers are central in preserving rehabilitation gains and the long-term well-being of stroke survivors, but commonly report a lack of support and a reduced quality of life, with the most important determinants of quality of life being age and the patients' functional status. ${ }^{57}$ Caring for stroke survivors can be especially stressful because of the variety of neurological impairments caused by the stroke, including motor, sensory, visual, language, cognitive and affective problems.

In contrast to caregivers of persons with other chronic conditions such as dementia or cancer, caregivers of stroke survivors are thrust into this role with little time to learn or grow into the necessary skills. Common fears specific to stroke caregivers are caused by the uncertainty of prognosis with the fear of another stroke, and the feeling of abandonment, especially when their loved one is unable to communicate. Caregiver's needs include information provision, managing emotions, social support, health maintenance and practical problem solving. Training caregivers in their new 
Table 1. Management of common post-stroke symptoms

\begin{tabular}{l}
\hline Symptom \\
\hline Pain \\
Central post-stroke p \\
\\
Hemiplegic shoulder pain spasticity \\
Painful sperical \\
Physical \\
Fatigue \\
Incontinence \\
Pleep-disordered \\
Preathing \\
Depression \\
Sexual dysfunction
\end{tabular}

Recommendations

LoE*

1a. Amitryptiline ${ }^{13}$ : start $10-25 \mathrm{mg} /$ day; end $\geq 75 \mathrm{mg} /$ day

II

1b. Lamotrigine ${ }^{15}$ : start $25 \mathrm{mg} /$ day, slow taper over $\sim 8$ weeks to $200 \mathrm{mg} /$ day

2a. Gabapentin: start $100 \mathrm{mg}$ id, increase over 14 days to 800 tid $^{14,17}$

2b. SNRIs (venlafaxine) ${ }^{14}$

4. Opioids, ${ }^{18}$ pregabalin $^{16}$ and carbamazepine ${ }^{13}$ probably ineffective

Shoulder sling during ambulation; ice, heat, soft tissue massage; NSAIDs acutely and before exercise Intramuscular electrical stimulation, intra-articular steroid injections, Botox $\mathrm{A}^{22,23}$

1. Physical therapy, antispastic positioning and range of motion exercises

2. Oral baclofen, tizanidine, dantrolene probable benefit ${ }^{6}$

Non-pharmacologic: diet, exercise, sleep-hygiene, assistive technologies

Pharmacologic: Modafinil $200 \mathrm{mg}$ po qday ${ }^{29}$; Methylphenidate $18 \mathrm{mg}$ po qday ${ }^{30}$

Urinary: behavioral interventions (timed voiding, pelvic floor muscle training) + professional input

(structured assessment, management of care, specialist continence nursing). Cochrane review 2008: no pharmacotherapy proven to help ${ }^{3}$

Fecal: bowel regimen (e.g., stimulant laxative such as bisacodyl or senna + osmolar agent such as milk of magnesia or polyethylene glycol. Avoid dehydration, polypharmacy

Lamotrigine (start $25 \mathrm{mg}$ /day, slow taper to $200 \mathrm{mg}$ /day)

Gabapentin (start $100 \mathrm{mg}$ tid, increase over 14 days to $600 \mathrm{tid}$ )

Levetiracetam (start $500 \mathrm{mg}$ bid, may increase to $1,000 \mathrm{mg}$ bid)

Carbamazepine (start $100 \mathrm{mg}$ bid, increase over 4 weeks to $400 \mathrm{mg}$ po bid) $)^{39,40}$

Primary prevention of PSS is not recommended ${ }^{2}$

Acknowledge and provide necessary resources: www.stroke.org ("Hope: The Stroke Recovery Guide"); www.sexualhealth.com ("Disability \& Chronic Conditions") 42

Sildenafil (Viagra) in a low dose $(25 \mathrm{mg})$ is probably safe ${ }^{43}$

Obstructive sleep apnea: CPAP for stroke and TIA patients with moderate to severe OSA, daytime symptoms and high cardiovascular risk profile, although mixed results ${ }^{44}$

1. Psychotherapy: behavioral interventions: identifying symptoms/causes of depression + identifying/ planning pleasant activities ${ }^{46,47,50}$

2. Antidepressant medications - mixed results, we suggest SSRI, i.e., Citalopram or Fluoxetine $20 \mathrm{mg}$ qday,

increase to $40 \mathrm{mg} /$ day $^{52}$. Nortryptiline ${ }^{62}$

Mixed results: Fluoxetine (benefit ${ }^{63,64}$; no effect ${ }^{62,65}$.

Probable benefit: Reboxetine ${ }^{49}$; FEWP ${ }^{64}$

No effect: Sertraline, ${ }^{66}$ Nefiracetam ${ }^{6}$

Anxiety

1. Generalized anxiety or panic pattern, especially when comorbid with depression: antidepressant medications, consider SSRI (as in depression)

2. Severe anxiety, especially when lifespan is limited. Anxiolytics,, e.g., Lorazepam start $0.5-1 \mathrm{mg}$ po or iv; use considerately as sedative effects

3. If comorbid with delirium or dementia, consider antipsychotics such as Haloperidol. Other non-

pharmacologic treatments that may be useful include biofeedback, acupuncture, hypnosis and cognitive behavioral therapy

1. Antidepressant medication if severe ${ }^{50}$

Emotionalism

2. Neudexta - not studied in stroke population; approved for patients with ALS or MS ${ }^{51}$

(II) $\dagger$

(II)

II, III

IV

IV

IV

IV

IV

IV

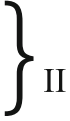

IV

IV

II

II/III

Caregiver's needs include information provision, managing emotions, social support, health maintenance and practical problem solving. Consider referral to a local social worker. A valuable resource can be found at http://www.strokeassociation.org/STROKEORG/LifeAfterStroke/Life-After-Stroke_UCM_308546_SubHomePage.jsp

Care giving and
receiving§
Spiritual
Spiritual Care§

Be perceptive to different traditions or beliefs, call on chaplain or spiritual care provider. Ask patients about possible spiritual or religious beliefs

*LoE, level of evidence

$\dagger$ Gabapentin and Venlafaxine have been studied for the use in neuropathic pain, but not specifically for central post-stroke pain

FEWP, Free Easy Wanderer Plus, Chinese herbal formula

$\$ N$ either "Care giving and receiving" nor "Spiritual care" were subject to the systematic literature search, but are included in the table for completeness without a LoE column

Class I evidence: prospective, randomized, controlled clinical trial with masked outcome assessment, in a representative population. The following are required: (1) primary outcome clearly specified; (2) exclusion/inclusion criteria clearly defined; (3c adequate accounting for drop-outs and cross-overs with low numbers to minimize bias; (4) relevant baseline characteristics are presented and substantially equivalent. Class II evidence: prospective matched group cohort study in a representative population with masked outcome assessment that meets (1) to (2) above OR a randomized controlled trial that lacks one of the criteria. Class III evidence: all other controlled trials (including well-defined natural history controls or patients serving their own controls) in a representative population, where outcome is independently assessed or independently derived by objective outcome measurement. Class IV evidence: evidence from uncontrolled studies, case series, case reports or expert opinion 
role has been shown to reduce perceived and actual burden while improving psychosocial outcomes in both caregivers and patients. ${ }^{58}$ Over $90 \%$ of caregivers also reported that their experience as a stroke caregiver had increased their appreciation of life. ${ }^{57}$ We recommend consultation with a local social worker familiar with resources in the patient's community to ensure that all opportunities are explored. A valuable resource for caregivers can be found at http://www.strokeassociation. org/STROKEORG/LifeAfterStroke/Life-After-Stroke_ UCM_308546_SubHomePage.jsp.

\section{SPIRITUAL, EXISTENTIAL SYMPTOMS}

Spiritual Care. Since patient and family suffering frequently extends beyond physical and psychological, spiritual care is a fundamental component of palliative care. ${ }^{59}$ Faced suddenly with their own mortality, stroke survivors and their families tend to review their lives and search for a sense of purpose and sometimes closure. In the broadest sense, spiritual care is the emotionally sensitive, empathetic care of the human "spirit" and is not specific to religion. Spirituality is not the same for every patient, and it is important to be perceptive to different cultural and religious traditions, to recognize spiritual distress or religious struggle, and to call on the expertise of a chaplain or other spiritual care provider when necessary. Religious or not, most patients appreciate a carefully worded inquiry about their spiritual or religious beliefs in the event that they become severely ill. ${ }^{60}$

Expressing a Wish to Die. Occasionally, stroke patients express a wish to die. These requests may be rare and are based on anecdotal evidence only, but they need to be taken seriously and they should not be "overnormalized" ("Everyone would feel the same way") or "overmedicalized" ("This is clear psychopathology"). ${ }^{61}$ Exploring such requests with statements like, "Can you tell me what you mean by that?" will often uncover one of the following underlying reasons: (1) unrecognized or undertreated physical symptoms, (2) psychosocial crisisfear of being a social or financial burden, (3) spiritual crisis and (4) clinical depression. Although post-stroke depression is common, such requests in the acute setting are often cries for help indicating emergent psychosocial or spiritual crises.

\section{CONCLUSIONS}

Nearly 5 million stroke survivors are alive in the US. ${ }^{1}$ Once past the acute and rehabilitation phase, they face a myriad of symptoms, including but not limited to anxiety, central pain, delirium, depression, emotionalism, fatigue, hemiplegic shoulder pain, incontinence, post-stroke seizures, sexual dysfunction, sleep-disordered breathing and spasticity. Most of these symptoms, if recognized, can be treated or palliated, leading to profound improvement in the patient's quality of life. We need further research to ensure high-quality management of patient symptomatology post-stroke. As our population ages, more and more health care practitioners will be involved in post-stroke care. Research in this important area needs to increase in parallel with provider responsibility, arming the practitioner with evidence rather than conjecture.

Financial Disclosures/Potential Conflicts of Interest: $C J$ Creutzfeldt, none; RG Holloway, consultancy with American Academy of Neurology (Associate Editor, Neurology Today) and Milliman Guideline, Inc. (Reviewer, Neurology Guidelines); M Walker, none.

Corresponding Author: Claire J. Creutzfeldt, MD; Department of Neurology, University of Washington Harborview Medical Center, Box 359775, 325 Ninth Ave, Seattle, WA 98104-2499, USA (e-mail: clairejc@uw.edu).

\section{REFERENCES}

1. AHA/ASA. Heart Disease and Stroke Statistics - 2010 Update; 2010.

2. Adams HP Jr, del Zoppo G, Alberts MJ, et al. Guidelines for the early management of adults with ischemic stroke: a guideline from the American Heart Association/American Stroke Association Stroke Council, Clinical Cardiology Council, Cardiovascular Radiology and Intervention Council, and the Atherosclerotic Peripheral Vascular Disease and Quality of Care Outcomes in Research Interdisciplinary Working Groups: the American Academy of Neurology affirms the value of this guideline as an educational tool for neurologists. Stroke. 2007;38:1655-1711.

3. Morgenstern LB, Hemphill JC 3rd, Anderson C, et al. Guidelines for the management of spontaneous intracerebral hemorrhage: a guideline for healthcare professionals from the American Heart Association/ American Stroke Association. Stroke. 2010;41:2108-2129.

4. Langhorne P, Coupar F, Pollock A. Motor recovery after stroke: a systematic review. Lancet Neurol. 2009;8:741-754.

5. Langhorne P, Bernhardt J, Kwakkel G. Stroke rehabilitation. Lancet. 2011:377:1693-1702.

6. Duncan PW, Zorowitz R, Bates B, et al. Management of Adult Stroke Rehabilitation Care: a clinical practice guideline. Stroke. 2005;36:e100 e143.

7. Stevens T, Payne SA, Burton C, Addington-Hall J, Jones A. Palliative care in stroke: a critical review of the literature. Palliat Med. 2007;21:323-331.

8. Edlund WGG, So Y, Franklin G. Clinical Practice Guideline Process Manual. online; 2004.

9. WHO. Available at: http://www.who.int/cancer/palliative/definition/en/. Accessed 12/07/2011.

10. Kehayia E, Korner-Bitensky N, Singer F, et al. Differences in pain medication use in stroke patients with aphasia and without aphasia. Stroke. 1997;28:1867-1870.

11. Jönsson AC, Lindgren I, Hallström B, Norrving B, Lindgren A. Prevalence and intensity of pain after stroke: a population based study focusing on patients' perspectives. J Neurol Neurosurg Psychiatry. 2006;77:590-595.

12. Klit H, Finnerup NB, Jensen TS. Central post-stroke pain: clinical characteristics, pathophysiology, and management. Lancet Neurol. 2009;8:857-868.

13. Leijon G, Boivie J. Central post-stroke pain-a controlled trial of amitriptyline and carbamazepine. Pain. 1989;36:27-36.

14. Saarto T, Wiffen PJ. Antidepressants for neuropathic pain. Cochrane Database Syst Rev. 2007:4:CD005454 
15. Vestergaard K, Andersen G, Gottrup H, Kristensen BT, Jensen TS. Lamotrigine for central poststroke pain: a randomized controlled trial. Neurology. 2001;56:184-190.

16. Kim JS, Bashford G, Murphy TK, Martin A, Dror V, Cheung R. Safety and efficacy of pregabalin in patients with central post-stroke pain. Pain. 2011;152:1018-1023.

17. Serpell MG, Neuropathic pain study group. Gabapentin in neuropathic pain syndromes: a randomised, double-blind, placebo-controlled trial. Pain. 2002;99:557-566.

18. Frese A, Husstedt IW, Ringelstein EB, Evers S. Pharmacologic treatment of central post-stroke pain. Clin J Pain. 2006;22:252-260.

19. Lindgren I, Jonsson AC, Norrving B, Lindgren A. Shoulder pain after stroke: a prospective population-based study. Stroke. 2007;38:343348.

20. Van Peppen RP, Kwakkel G, Wood-Dauphinee S, Hendriks HJ, Van der Wees PJ, Dekker J. The impact of physical therapy on functional outcomes after stroke: what's the evidence? Clin Rehabil. 2004;18:833862 .

21. Singh JA, Fitzgerald PM. Botulinum toxin for shoulder pain. Cochrane Database Syst Rev. 2010;9:CD008271.

22. Koog YH, Jin SS, Yoon K, Min BI. Interventions for hemiplegic shoulder pain: systematic review of randomised controlled trials. Disabil Rehabil. 2010;32:282-291.

23. Gamble GE, Barberan E, Laasch HU, Bowsher D, Tyrrell PJ, Jones AK. Poststroke shoulder pain: a prospective study of the association and risk factors in 152 patients from a consecutive cohort of 205 patients presenting with stroke. Eur J Pain. 2002;6:467-474.

24. Lapeyre E, Kuks JB, Meijler WJ. Spasticity: revisiting the role and the individual value of several pharmacological treatments. NeuroRehabilitation. 2010;27:193-200.

25. Shaw LC, Price CI, van Wijck FM, et al. Botulinum Toxin for the Upper Limb After Stroke (BoTULS) Trial: Effect on Impairment, Activity Limitation, and Pain. Stroke. 2011;42:1371-1379.

26. Appelros P. Prevalence and predictors of pain and fatigue after stroke: a population-based study. Int J Rehabil Res. 2006;29:329-333.

27. Mead GE, Graham C, Dorman P, Bruins SK, Lewis SC, Dennis MS, Sandercock PA. UK Collaborators of IST. Fatigue after stroke: baseline predictors and influence on survival. Analysis of data from UK patients recruited in the International Stroke Trial. PLoS One. 2011;6:e16988.

28. Winward C, Sackley C, Metha Z, Rothwell PM. A population-based study of the prevalence of fatigue after transient ischemic attack and minor stroke. Stroke. 2009;40:757-761.

29. Flinn NA, Stube JE. Post-stroke fatigue: qualitative study of three focus groups. Occup Ther Int. 2010;17:81-91.

30. McGeough E, Pollock A, Smith LN, et al. Interventions for post-stroke fatigue. Cochrane Database Syst Rev 2009:CD007030.

31. Brioschi A, Gramigna S, Werth E, et al. Effect of modafinil on subjective fatigue in multiple sclerosis and stroke patients. Eur Neurol. 2009;62:243-249.

32. Peuckmann V, Elsner F, Krumm N, Trottenberg P, Radbruch L. Pharmacological treatments for fatigue associated with palliative care. Cochrane Database Syst Rev 2010:CD006788.

33. Nakayama H, Jorgensen HS, Pedersen PM, Raaschou HO, Olsen TS. Prevalence and risk factors of incontinence after stroke. The Copenhagen Stroke Study. Stroke. 1997;28:58-62.

34. Thomas LH, Cross S, Barrett J, et al. Treatment of urinary incontinence after stroke in adults. Cochrane Database Syst Rev 2008: CD004462.

35. Rao SS, Go JT. Update on the management of constipation in the elderly: new treatment options. Clin Interv Aging. 2010;5:163-171.

36. Bladin CF, Alexandrov AV, Bellavance A, et al. Seizures after stroke: a prospective multicenter study. Arch Neurol. 2000;57:1617-1622.

37. Berges S, Moulin T, Berger E, et al. Seizures and epilepsy following strokes: recurrence factors. Eur Neurol. 2000;43:3-8.

38. Kwan J, Wood E. Antiepileptic drugs for the primary and secondary prevention of seizures after stroke. Cochrane Database Syst Rev 2010: CD005398

39. Ryvlin P, Montavont A, Nighoghossian N. Optimizing therapy of seizures in stroke patients. Neurology. 2006;67:S3-S9.

40. Perucca E, Tomson T. The pharmacological treatment of epilepsy in adults. Lancet Neurol. 2011;10(5):446-456.

41. Tamam Y, Tamam L, Akil E, Yasan A, Tamam B. Post-stroke sexual functioning in first stroke patients. Eur J Neurol. 2008;15:660-666.

42. Kautz DD. Hope for love: practical advice for intimacy and sex after stroke. Rehabil Nurs. 2007;32:95-103.
43. Silver B, McCarthy S, Lu M, et al. Sildenafil treatment of subacute ischemic stroke: a safety study at $25-\mathrm{mg}$ daily for 2 weeks. J Stroke Cerebrovasc Dis. 2009; 18:381-383.

44. Hermann DM, Bassetti CL. Sleep-related breathing and sleep-wake disturbanes in ischemic stroke. Neurology. 2009;73:1313-1322.

45. Chan W, Coutts SB, Hanly P. Sleep apnea in patients with transient ischemic attack and minor stroke: opportunity for risk reduction of recurrent stroke? Stroke. 2010;41:2973-2975.

46. Hackett ML, Anderson CS, House A, Xia J. Interventions for treating depression after stroke. Cochrane Database Syst Rev 2008:CD003437.

47. Hackett ML, Anderson CS, House A, Halteh C. Interventions for preventing depression after stroke. Cochrane Database Syst Rev 2008: CD003689.

48. Chollet F, Tardy J, Albucher JF, et al. Fluoxetine for motor recovery after acute ischaemic stroke (FLAME): a randomised placebo-controlled trial. Lancet Neurol. 2011;10:123-130.

49. Rampello L, Alvano A, Chiechio S, Raffaele R, Vecchio I, Malaguarnera M. An evaluation of efficacy and safety of reboxetine in elderly patients affected by "retarded" post-stroke depression. A random, placebo-controlled study. Arch Gerontol Geriatr. 2005;40:275-285.

50. Mitchell PH, Veith RC, Becker KJ, et al. Brief psychosocial-behavioral intervention with antidepressant reduces poststroke depression significantly more than usual care with antidepressant: living well with stroke: randomized, controlled trial. Stroke. 2009;40:3073-3078.

51. Castillo CS, Starkstein SE, Fedoroff JP, Price TR, Robinson RG. Generalized anxiety disorder after stroke. J Nerv Ment Dis. 1993;181:100-106.

52. Andersen G, Vestergaard $\mathbf{K}$, Lauritzen $\mathbf{L}$. Effective treatment of poststroke depression with the selective serotonin reuptake inhibitor citalopram. Stroke. 1994;25:1099-1104.

53. Lonergan E, Britton AM, Luxenberg J, Wyller T. Antipsychotics for delirium. Cochrane Database Syst Rev 2007:CD005594.

54. House AO, Hackett ML, Anderson CS, Horrocks JA. Pharmaceutical interventions for emotionalism after stroke. Cochrane Database Syst Rev 2010:CD003690.

55. Dextromethorphan/Quinidine (nuedexta) for pseudobulbar affect. Med Lett Drugs Ther. 2011;53:46-47

56. Van den Heuvel ET, de Witte LP, Schure LM, Sanderman R. Meyboomde Jong B. Risk factors for burn-out in caregivers of stroke patients, and possibilities for intervention. Clin Rehabil. 2001;15:669-677.

57. Han B, Haley WE. Family caregiving for patients with stroke. Review and analysis. Stroke. 1999;30:1478-1485.

58. Kalra L, Evans A, Perez I, et al. Training carers of stroke patients: randomised controlled trial. BMJ. 2004;328:1099.

59. Puchalski C, Ferrell B, Virani R, et al. Improving the quality of spiritual care as a dimension of palliative care: the report of the Consensus Conference. J Palliat Med. 2009;12:885-904.

60. Ehman JW, Ott BB, Short TH, Ciampa RC, Hansen-Flaschen J. Do patients want physicians to inquire about their spiritual or religious beliefs if they become gravely ill? Arch Intern Med. 1999;159:1803-1806.

61. Quill TE, Lo B, Brock DW. Palliative options of last resort: a comparison of voluntarily stopping eating and drinking, terminal sedation, physician-assisted suicide, and voluntary active euthanasia. JAMA. 1997;278:2099-2104.

62. Robinson RG, Schultz SK, Castillo C, et al. Nortriptyline versus fluoxetine in the treatment of depression and in short-term recovery after stroke: a placebo-controlled, double-blind study. Am J Psychiatry. 2000;157:351-359.

63. Wiart L, Petit H, Joseph PA, Mazaux JM, Barat M. Fluoxetine in early poststroke depression: a double-blind placebo-controlled study. Stroke. 2000;31:1829-1832.

64. Li LT, Wang SH, Ge HY, Chen J, Yue SW, Yu M. The beneficial effects of the herbal medicine Free and Easy Wanderer Plus (FEWP) and fluoxetine on post- stroke depression. J Altern Complement Med. 2008;14:841846

65. Fruehwald S, Gatterbauer E, Rehak P, Baumhack1 U. Early fluoxetine treatment of post-stroke depression-a three-month double-blind placebo-controlled study with an open-label long-term follow up. J Neurol. 2003;250:347-351

66. Murray V, von Arbin M, Bartfai A, et al. Double-blind comparison of sertraline and placebo in stroke patients with minor depression and less severe major depression. J Clin Psychiatry. 2005;66:708-716.

67. Robinson RG, Jorge RE, Clarence-Smith K. Double-blind randomized treatment of poststroke depression using nefiracetam. J Neuropsychiatry Clin Neurosci. 2008;20:178-184. 